\title{
Biofertilizantes pulverizados nas folhas e no sulco de semeadura na cultura do amendoim
}

\author{
Submetido - 10 jul. 2021 \\ Aprovado - 01 out 2021 \\ Publicado - 20 dez. 2021
}

http://dx.doi.org/10.52755/sas.v.2iedesp1.140 Universidade Estadual Paulista - Unesp.E-mail: olavobetiol96@gmail.com.

\section{Letícia Pelicioni Palviqueres (D)}

Graduanda em Agronomia - Centro Universitário Moura Lacerda, Ribeirão Preto, SP. E-mail: le.palviqueres@gmail.com.

Graduando em Agronomia - Centro Universitário Moura Lacerda, Ribeirão Preto, SP. E-mail: fabiofioriruiz208@gmail.com.

Élcio Rios Pérez Leal(i)

Eng. Agrônomo, Mestrando em Agronomia, - Faculdades de Ciências e Veterinárias - FCAV/ Universidade Estadual Paulista - Unesp. E-mail: elciorpleal@gmail.com.

Denizart Bolonhezi ${ }^{(1)}$ Dr., Pesquisador Científico - Instituto Agronômico de Campinas - IAC, Centro de Cana, Ribeirão Preto, SP.E-mail: denizart@iac.sp.gov.br.

\section{RESUMO}

Os biofertilizantes são insumos importantes para obtenção de altas produtividades na cultura do amendoim, pois contribuem para reduzir os estresses bióticos e abióticos, bem como estimulam a simbiose com bactérias fixadoras de nitrogênio e outros microrganismos benéficos. Com objetivo de estudar o efeito do biofertilizante Vorax® e inoculante Atmo® sobre algumas características agronômicas dos cultivares de amendoim IAC OL-3 e IAC-503, foram instalados ensaios de campo em LATOSSOLO Vermelho eutroférrico, textura argilosa, situado no IAC em Ribeirão Preto/SP. Com delineamento em blocos casualizados com quatro repetições, na safra 2019/20, foram estudados 5 tratamentos na cultivar IAC OL-3: controle (T1); $50 \mathrm{~mL} \mathrm{ha}{ }^{-1}$ de Vorax® pulverizados aos 25 (T2); aos 25 e 50 (T3), 25, 50 e 80 dias após a semeadura (T4), bem como o biofertilizante na dose de $30 \mathrm{~mL}$ ha-1 pulverizado em conjunto com os fungicidas a partir dos 45 DAS (T5). Na safra 2020/21, o ensaio com mesmo delineamento, testou 07 tratamentos na cultivar IAC 503: controle (T1); Atmo ${ }^{\circledR}$ (300 mL ha-1) no sulco de semeadura + Synflex@ $150 \mathrm{~mL} \mathrm{ha}^{-1}$ (T2); T2 + MQL007 (50 mL ha-1) no sulco de semeadura (T3); T3 + MQL007 (50 mL ha-1) pulverizado aos 25 DAS (T4); MQL007 (50 mL ha-1) pulverizado aos 25 DAS (T5); Vorax ${ }^{\circledR}\left(50 \mathrm{~mL} \mathrm{ha}^{-1}\right)$ pulverizado aos 25, 50 e 80 DAS (T6); T6 + pulverização aos 100 DAS (T7). Conclui-se para as condições dos experimentos que: três pulverizações de Vorax ${ }^{\circledR}\left(50 \mathrm{~mL} \mathrm{ha}^{-1}\right)$ proporcionaram aumentos significativos na ordem de $27 \%$ e $24 \%$, respectivamente para os cultivares IAC OL-3 e IAC 503, bem como a aplicação no sulco do inoculante Atmo $\AA^{\circledR}$ + Synflex® associado com bioestimulante MQLO07 proporcionou ganhos de $27 \%$ na produtividade de vagens do IAC 503.

Palavras-chave: Arachis hypogaea L; Produtividade de vagens; Biomassa vegetativa; Ácido glutâmico.

\section{Biofertilizers sprayed on leaves and seed furrow in peanut}

$$
\text { crops }
$$

Este é um trabalho de acesso aberto e distribuído sob os Termos da Creative

Commons Attribution Attribution-NonCommercial-ShareAlike 4.0 International. 


\section{ABSTRACT}

Biofertilizers are important substances for obtaining high yields in peanut crops, because can contribute to reducing biotic and abiotic stresses, as well as stimulating symbiosis with nitrogen-fixing bacteria and other beneficial microorganisms. In order to study the effect of Vorax ${ }^{\circledR}$ biofertilizer and Atmo ${ }^{\circledR}$ inoculant on some agronomic characteristics of peanut cultivars IAC OL-3 and IAC-503, field trials were carried out in LATOSSOLO Vermelho eutroférrico, clayey texture, located at the IAC in Ribeirão Preto/SP. In a randomized block experimental design with four replications, in the 2019/20 season, 5 treatments were studied in the cultivar IAC OL-3: control (T1); 50 mL ha-1 of Vorax® sprayed at 25 (T2); at 25 and 50 (T3), 25, 50 and 80 days after sowing (T4), as well as biofertilizer at a dose of $30 \mathrm{~mL} \mathrm{ha}^{-1}$ sprayed together with fungicides from 45 DAS (T5). In the 2020/21 season, the trial with the same design tested 07 treatments in the cultivar IAC 503: control (T1); Atmo® $\left(300 \mathrm{~mL} \mathrm{ha}^{-1}\right)$ in the seeding furrow + Synflex® $150 \mathrm{~mL} \mathrm{ha-1}$ (T2); T2 + MQL007 (50 mL ha-1) in the seeding furrow (T3); T3 + MQL007 (50 mL ha-1) sprayed at 25 DAS (T4); MQL007 (50 mL ha-1) sprayed at 25 DAS (T5); $\operatorname{Vorax}{ }^{\circledR}\left(50 \mathrm{~mL} \mathrm{ha^{-1 } )}\right.$ sprayed at 25, 50 and 80 DAS (T6); T6 + spraying at 100 DAS (T7). It is concluded for the conditions of the experiments that: three sprays of $\operatorname{Vorax} \circledast\left(50 \mathrm{~mL} \mathrm{ha}^{-1}\right)$ provided significant increases in the order of $27 \%$ and $24 \%$, respectively for the cultivars IAC OL-3 and IAC 503, as well as the application in the furrow of the inoculant Atmo® + Synflex® associated with biostimulant MQL007 provided 27\% gains in the productivity of IAC 503 pods.

Keywords: Arachis hypogaea L.; Pod productivity; Vegetative biomass; Glutamic acid.

Biofertilizantes rociados sobre hojas y surcos de semillas en cultivos de maní

\section{RESUMEN}

Los biofertilizantes son insumos importantes para la obtención de altos rendimientos en los cultivos de maní, ya que contribuyen a reducir los estreses bióticos y abióticos, así como a estimular la simbiosis con bacterias fijadoras de nitrógeno y otros microorganismos beneficiosos. Para estudiar el efecto del biofertilizante Vorax $\circledast$ e inoculante Atmo ${ }^{\circledR}$ sobre algunas características agronómicas de los cultivares de maní IAC OL-3 e IAC-503, se realizaron ensayos de campo en suelo clasificado como LATOSSOLO Vermelho eutroférrico, textura arcillosa, ubicada en el IAC en Ribeirão Preto / SP. En un diseño de bloques al azar con cuatro repeticiones, en la temporada 2019/20 se estudiaron 5 tratamientos en el cultivar IAC OL3: control (T1); $50 \mathrm{~mL}$ ha $^{-1}$ de Vorax ${ }^{\circledR}$ asperjado a 25 (T2); a los 25 y 50 (T3), 25, 50 y 80 días después de la siembra (T4), así como biofertilizante a dosis de $30 \mathrm{~mL} \mathrm{ha}^{-1}$ asperjado junto con fungicidas de 45 DAS (T5). En la temporada 2020/21, el ensayo con el mismo diseño probó 07 tratamientos en el cultivar IAC 503: control (T1); Atmo® $\left(300 \mathrm{~mL} \mathrm{ha}^{-1}\right)$ en el surco de siembra + Synflex® $150 \mathrm{~mL} \mathrm{ha-1}$ (T2); T2 + MQL007 (50 mL ha-1) en el surco de siembra (T3); T3 + MQL007 (50 $\mathrm{mL} \mathrm{ha}^{-1}$ ) rociado a 25 DAS (T4); MQL007 (50 $\mathrm{mL} \mathrm{ha}^{-1}$ ) rociado a 25 DAS (T5); Vorax® (50 $\mathrm{mL}$ $h^{-1}$ ) asperjado a 25, 50 y 80 DAS (T6); T6 + pulverización a 100 DAS (T7). Se concluye para las condiciones de los experimentos que: tres aspersiones de Vorax ${ }^{\circledR}\left(50 \mathrm{~mL} \mathrm{ha}^{-1}\right)$ proporcionaron incrementos significativos del orden del $27 \%$ y $24 \%$, respectivamente para los cultivares IAC OL-3 e IAC 503, así como ya que la aplicación en el surco del inoculante Atmo® + Synflex® asociado al bioestimulante MQL007 proporcionó ganancias del $27 \%$ en la productividad de las vainas IAC 503.

Palabras clave: Arachis hypogaea L.; Productividad de la vaina; Biomasa vegetativa; Ácido glutamico.

\section{Introdução}

Nos últimos 20 anos, a cultura do amendoim incorporou diversas novas tecnologias, as quais têm contribuído para aumentar a área cultivada, a produção e o rendimento em $47,6 \%, 59,5 \%$ e $22,7 \%$, respectivamente. A 
produção brasileira de amendoim foi de 597 mil toneladas na última safra, concentrada no estado de São Paulo, apresenta área cultivada de aproximadamente 156 mil hectares (CONAB, 2021).

As exportações têm impulsionado o crescimento da cultura do amendoim, mercado exigente que demanda introdução de novas tecnologias de produção que confiram maior qualidade do produto. Para atender às exigências têm aumentado o consumo de biopesticidas e biofertilizantes. Existem muitas definições para biofertilizantes, mas de acordo com Vessey (2003), é considerada todo insumo que contém microrganismos vivos ou compostos extraídos, os quais quando aplicados na superfície das plantas, sementes e solos, colonizam a rizosfera ou interior dos tecidos vegetais, promovendo o crescimento devido ao aumento do suprimento ou disponibilidade de nutrientes essenciais. Contudo, para nossas condições, muitas vezes esses insumos são considerados de forma genérica como fertilizantes foliares. No caso de biofertilizantes compostos por extratos de plantas e algas, sua ação pode ser no aparato fisiológico da planta alvo ou indireta por intermédio da produção de compostos (flavonoides, ácidos orgânicos, compostos fenólicos) que são exsudados pelas raízes e favorecem a interação com microrganismos em nível da rizosfera (WANG et al., 2021)

É importante esclarecer que a espécie Arachis hypogaea (L.) é nativa da América do Sul, fato que denota uma relação mais estreita com a biota existente nos solos. Por essa razão, os inoculantes com bactérias fixadoras de nitrogênio (FBN), testados no passado, mostravam-se pouco eficientes, pois há competição com estirpes nativas existentes nos solos. Porém deve-se considerar que a FBN para essa oleaginosa, supri somente $70 \%$ da demanda requerida pela planta. Por conseguinte, tendo em vista os altos potenciais produtivos dos genótipos modernos, existe a necessidade de retomar as pesquisas com inoculantes, como estratégia para fornecer as quantidades de nitrogênio exigidas. Vale ressaltar que, existem tecnologias que aumentam a viabilidade das bactérias e asseguram maior eficiência da FBN, com destaque às substâncias protetoras e os equipamentos de 
pulverização em sulco de semeadura. Além disso, posicionar o uso de biofertilizantes no sulco de semeadura evita danos mecânicos e perda do tegumento das sementes, bem como reduz contato das bactérias com os defensivos utilizados no tratamento.

Considerando o exposto, o presente trabalho teve como objetivos: estudar o efeito do biofertilizante $\operatorname{Vorax}^{\circledR} \mathrm{e}$ inoculante $A \mathrm{Atmo}^{\circledR}$ sobre algumas características agronômicas e nodulação nos cultivares de amendoim IAC OL-3 e IAC-503, para as condições edafoclimáticas de Ribeirão Preto/SP.

\section{Material e métodos}

Experimentos conduzidos em campo foram instalados nas safras 2019/20 e 2020/21 em condição de LATOSSOLO Vermelho eutroférrico, textura argilosa, em área do IAC na cidade de Ribeirão Preto/SP, com histórico de 10 anos de milho em semeadura direta. Na safra 2019/20, utilizou-se delineamento experimental blocos casualizados com quatro repetições, para estudar o número entre aplicações do biofertilizante Vorax ${ }^{\circledR}$ (25\% ácido glutâmico, $4 \%$ de $N$ solúvel em água, obtido a partir da fermentação de melaço de cana-de-açúcar). Os tratamentos testados foram: T1- controle; T2 - $50 \mathrm{~mL} \mathrm{ha-1}$ de Vorax ${ }^{\circledR}$ pulverizados aos 25 dias após semeadura (DAS); T3 -T2 pulverizado aos 25 e 50 DAS; T4 - T3 pulverizado aos 25, 50 e 80 (DAS), T5 - Vorax ${ }^{\circledR}$ na dose de $30 \mathrm{~mL} \mathrm{ha}^{-1}$ pulverizado em conjunto com os fungicidas a partir dos 45 DAS. O cultivar IAC OL3 foi semeado (25/11/2019) em parcelas com 8 linhas de 5 metros no espaçamento $0,90 \mathrm{~m}$ entre linhas, sendo fornecido na semeadura, 12, $90 \mathrm{e}$ $40 \mathrm{~kg} \mathrm{ha}^{-1}$ de $\mathrm{N}, \mathrm{P}_{2} \mathrm{O}_{5}$ e $\mathrm{K}_{2} \mathrm{O}$, bem como o manejo fitossanitário constou de 10 pulverizações com fungicidas e quatro com fungicidas durante o ciclo. Após levantamento do estande final, as plantas foram colhidas (18/03/2020) e trilhadas com trilhadora mecânica para posterior determinação dos componentes da produtividade (número de vagens, rendimento de grãos, massa de 100 grãos e produtividade de vagens).

$\mathrm{Na}$ safra 2020/21, foi instalado ensaio com delineamento blocos casualizados e quatro repetições na mesma unidade do IAC, em solo com a 
mesma classificação, porém com histórico de 5 anos de cultivo de espécies leguminosas para adubação verde e duas safras de soja. Os tratamentos consistiram de: T1 - controle; T2 - Atmo ${ }^{\circledR}\left(300 \mathrm{~mL} \mathrm{ha}^{-1}\right)$ no sulco de semeadura + Synflex ${ }^{\circledast} 150 \mathrm{~mL} \mathrm{ha}^{-1} ;$ T3 - T2 + MQL007 (50 mL ha-1) no sulco de semeadura; T4 - T3 + MQL007 (50 mL ha-1) pulverizado aos 25 DAS; T5 MQL007 (50 mL ha ${ }^{-1}$ ) pulverizado aos 25 DAS (T5); T6 - Vorax ${ }^{\circledR}\left(50 \mathrm{~mL} \mathrm{ha}^{-1}\right)$ pulverizado aos 25, 50 e 80 DAS; T7 - T6 + pulverização aos 100 DAS. Semeou-se manualmente (01/12/2020) o cultivar IAC 503, utilizando-se parcelas com 06 linhas de 5 metros e espaçamento de 0,90 m. Foram fornecidos na linha de semeadura 15,90 e $30 \mathrm{~kg} \mathrm{ha}^{-1}$ de $\mathrm{N}, \mathrm{P}_{2} \mathrm{O}_{5}$ e $\mathrm{K}_{2} \mathrm{O}$, assim como foram realizadas 12 pulverizações com fungicidas e $04 \mathrm{com}$ inseticidas ao longo do ciclo. O arranquio (19/04/2021) e trilha (24/04/2021) foram mecanizados. Na colheita foram determinados em duas linhas úteis de 4 metros em cada parcela: a produtividade de vagens, de grãos, rendimento de grãos, massa de 100 grãos e classificação por peneira. Os dados obtidos nos dois ensaios foram submetidos à análise da variância e as médias comparadas pelo teste de Tukey ( $5 \%$ de probabilidade).

\section{Resultados e discussão}

Os resultados de produtividades de vagens e grãos referentes ao efeito do $\operatorname{Vorax}^{\circledR}$ pulverizados em diferentes momentos da cultura, encontram-se na Figura 1. Verifica-se que para produtividade de vagens houve diferença estatística entre os tratamentos, porém sem diferença para produtividade de grãos do cultivar IAC OL-3. Nota-se que em relação à testemunha, a aplicação de $50 \mathrm{~mL}$ ha $^{-1}$ aos 25,50 e 80 dias após a semeadura, proporcionou aumentos de $9 \%, 19 \%$ e $27 \%$ na produtividade de vagens. O número de vagens por planta foi o componente mais influenciado (resultado não apresentado) e que auxilia na explicação das maiores produtividades verificadas com a aplicação desse biofertilizante na cultura do amendoim. Wang et al. (2021), estudando efeito de fungos endofíticos sobre a nodulação do amendoim, concluíram que o microrganismo $P$. liquidambaris foi responsável pela produção de exsudados (ácidos orgânicos, compostos fenólicos, ácido glutâmico) nas raízes, os quais estimularam a simbiose com 
bactérias fixadoras de nitrogênio. Provavelmente, além dos efeitos já reportados pelos biofertilizantes em termos de aumento da fotossíntese e resistência com estresses bióticos e abióticos, a aplicação do Vorax ${ }^{\circledR}$ poderia ter estimulado a maior FBN no amendoim.
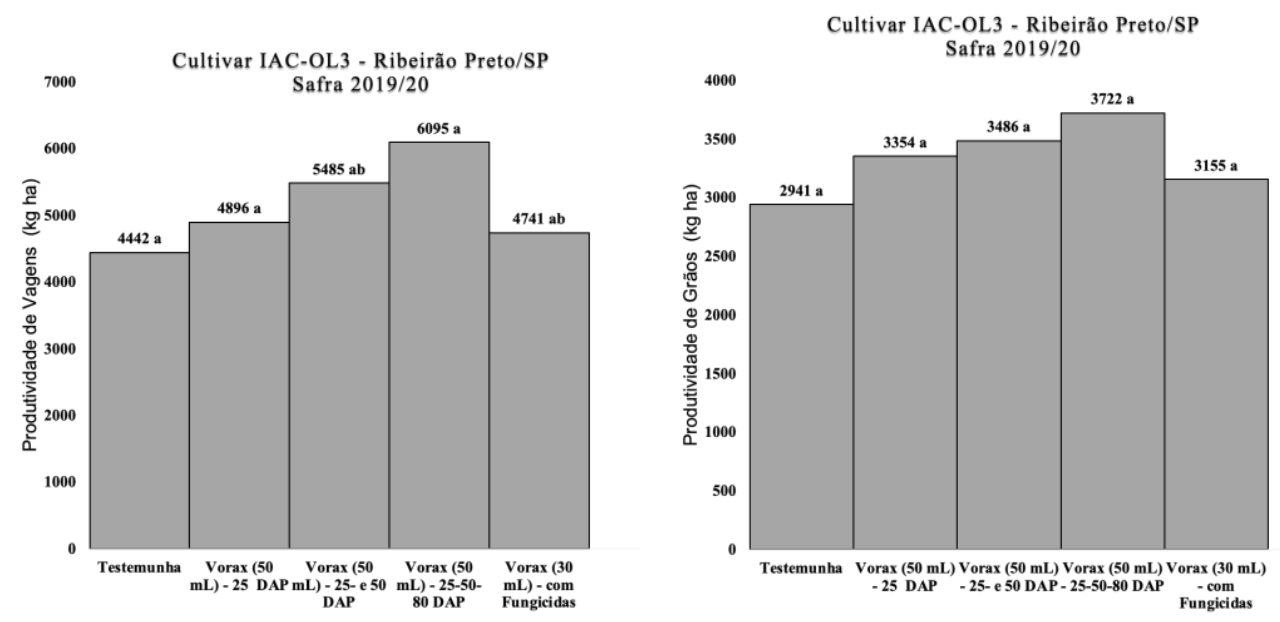

Figura 1. Produtividade de vagens e grãos do cultivar IAC OL3, submetido à aplicação de $\operatorname{Vorax}^{\circledR}$. Média de 4 repetições.

O aumento da produtividade de vagens com as três pulverizações do Vorax ${ }^{\circledR}$, também foi identificada na safra 2020/21 para a cultivar IAC 503, que apresentou ganhos de $25 \%$ em relação à testemunha. Além disso, nesse ensaio, pode-se observar aumento significativo na mesma magnitude com a aplicação no sulco do inoculante $\operatorname{Atmo}^{\circledR}\left(300 \mathrm{~mL} \mathrm{ha}^{-1}\right)$ associado com um protetor (Synflex ${ }^{\circledast} 150 \mathrm{~mL} \mathrm{ha}^{-1}$ ) e com outro biofertilizante (MQL007, 50 $\left.\mathrm{mL} \mathrm{ha}^{-1}\right)$. A baixa resposta em termos de número e massa seca de nódulos entre os tratamentos (resultados não apresentados), pode-se inferir que a proposta de realizar a aplicação no sulco é viável inclusive quando combinada com biofertilizantes. Steiner et al. (2020) concluiu que a coinoculação (Bradyrhizobium japonicum + Azospirillum brasiliense) aplicados no sulco proporcionaram aumentos de $24 \%$ na produtividade de vagens, em condições de solos arenosos no Cerrado brasileiro. 

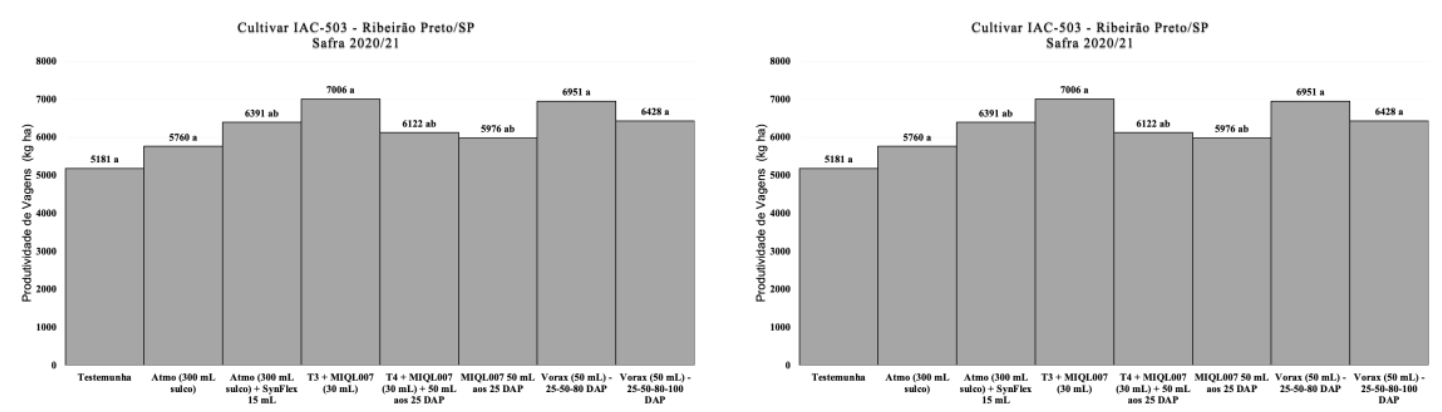

Figura 2. Produtividade de vagens e grãos do cultivar IAC 503, submetido à aplicação de inoculantes e biofertilizantes no sulco de semeadura e pulverizados na parte aérea. Média de 4 repetições.

\section{Conclusões}

Pulverizações de $\operatorname{Vorax}^{\circledR}$ aos 25, 50 e 80 dias após a semeadura, proporcionaram ganhos significativos na produtividade de vagens do amendoim IAC OL3. Aplicação no sulco de inoculante Atmo ${ }^{\circledR}+$ Synflex ${ }^{\circledR}+$ MIQL007 ou $\operatorname{Vorax}^{\circledR}(3 \mathrm{x})$, proporcionaram aumentos significativos de 26 e $24 \%$ na produtividade de vagens. 


\section{Referências}

CONAB. Acompanhamento da safra brasileira: grãos - Oitavo levantamento. Companhia Nacional de Abastecimento - Safra 2020/21, v. 8, n. 8, p. 1 115, 2021.

STEINER, F.; QUEIROZ, L.F.M.; ZUFFO, A.M.; SILVA, K.C.; LIMA, I.M.O. Peanut response to co-inoculation of Bradyrhizobium spp. and Azospirillum brasilense and molybdenum application in sandy soil of the Brazilian Cerrado. Agronomy Journal, v. 113, p. 623-632, 2020.

VESSEY, J.K. Plant growth promoting rhizobacteria as biofertilizers. Plant and Soil, v. 255, p. 571-586, 2003.

WANG, H.W.; MA, C.; XU, F.; LU, F.; ZHANG, W.; DAI, C.C. Root endophyte enhanced peanut rhizobia interaction is associated with regulation of root exudates. Microbiological Research, v. 250, n. 126765, 2021. doi: 10.1016/j.micres.2021.126765. 